\title{
PRISIONES E INTERNADOS: una comparación de los establecimientos penales en América del Norte y América Latina $^{1}$
}

\author{
Christopher Howard Birkbeck.
}

\begin{abstract}
El empleo reciente de términos como "warehouse prison" en Estados Unidos y "campo de concentración” en América Latina parecería indicar que las condiciones de privación de la libertad son distintas en ambas regiones. El análisis presentado aquí explora esas diferencias. Se comparan los establecimientos penales en América del Norte y América Latina a través de seis dimensiones relacionadas entre sí: la organización interna de los espacios, la vigilancia, el aislamiento, la supervisión, el control administrativo y la formalización de los procedimientos. En América del Norte, el control es asiduo (persistente, intrusivo y casi permanente); en América Latina, el control es somero (esporádico, indiferente y superficial). Si en América del Norte se habla de prisiones y encarcelamiento, en América Latina parece mejor hablar de internados judiciales e internación.

PALABRAS ClaVE: cárcel, prisión, internamiento, América del Norte, América Latina.
\end{abstract}

\section{INTRODUCCIÓN}

La proliferación de términos en el sector penal - "penitenciaría”, "prisión”, “cárcel”, “centro de corrección”, “centro de detención”, y otros parecidos - evidencia una diversidad considerable de perspectivas, y quizás alguna confusión sobre la naturaleza de la institución en cuestión. ¿Estos términos constituyen definiciones de los establecimientos penales, o prescripciones de lo que deben ser? ¿Denotan lo que pasa al interior de estos recintos, o simbolizan nuestras ideas (y esperanzas) sobre lo que debería pasar allí? Frente a estas dudas e inquietudes, algunos investigadores han optado por acuñar nuevos términos en un espíritu de realismo penológico.

En este sentido, es interesante observar que los investigadores estadounidenses hablan con cada

* Geógrafo. Doutor em Criminología. Professor de Criminologia da University of Salford, Reino Unido.

ESPaCH, Crescent House, Salford, M5 4WT, Reino Unido. c.h.birkbeck@salford.ac.uk

${ }^{1}$ Agradezco al programa sobre "Crime, Law and Governance in the Americas" de la Universidad de Florida su apoyo para la realización de este trabajo. Michael Welch, Odilza Lines y Eduardo Paes ofrecieron comentarios muy útiles sobre una versión anterior de este capítulo. vez mayor frecuencia del warehouse ("almacén") cuando se refieren a las prisiones de ese país (ver, por ejemplo, Toch, 1985; Fleisher, 1989; Robertson, 1997; Simon, 2000; Lynch, 2001; Irwin, 2004). Invocar al warehouse constituye un recurso semántico muy llamativo (¿cómo puede ser que una prisión se asemeja a un depósito de mercancía?) que nos invita a reconocer que los actuales recintos penales en Estados Unidos no hacen mucho más que proporcionar un encierro seguro de las personas condenadas por delitos. Organizados como las cajas que se guardan en los estantes de un almacén, los internos están sometidos a un régimen de control cuyo objetivo primordial es reducir los riesgos que significan para ellos mismos, para otros reclusos, para el personal del establecimiento y para la sociedad en general. Sin embargo (reza la crítica subyacente en esta terminología), en algún momento, estas personas serán liberadas (iredistribuidas como mercancía!) con todos los problemas que pueden esperarse después de haber pasado tanto tiempo en depósito.

En América Latina, donde la cantidad de estudios académicos y comentarios sobre el sector 
penal es apreciablemente menor que en América del Norte (un punto que retomaré en las páginas siguientes), el calificativo actual más llamativo para los establecimientos penales es "campo de concentración” (Caldeira, 2000; Wacquant, 2003; Kane and Tilsley, 2006). El impacto particular de esta designación se debe, obviamente, a su asociación con los campos de exterminio operados por los nazis en la Alemania de los años 1940. Aun cuando estos autores no crean que existan campos de concentración en la región, no hay duda que quieren llamar la atención sobre las duras condiciones de vida y la violencia que caracterizan a muchos centros penales de América Latina. Hay una crisis humanitaria en el sector penal que requiere pleno reconocimiento y acciones urgentes.

Warehouse y campo de concentración son términos que han surgido en ámbitos geográficos distintos. ¿Estas tácticas semánticas representan solamente el estilo lingüístico y la postura moral de sus autores, o denotan diferencias palpables en la naturaleza de la reclusión penal en ambas regiones? A esa inquietud se intenta dar una respuesta en este ensayo, el cual compara las instituciones penales en América del Norte y América Latina para aproximarse a la naturaleza de la privación de la libertad, entendiéndose por "naturaleza" la combinación particular de cualidades que imparte un carácter distintivo a cualquier fenómeno. Para adelantar una parte del planteamiento siguiente, el "almacén” y el "campo de concentración" enfrentan algunas dificultades como descriptores de sus realidades correspondientes; sin embargo, es indudable que, de modo general, indican diferencias importantes en la naturaleza de la privación de la libertad en cada región. Esas diferencias serán analizadas en detalle a lo largo de este trabajo y resumidas en la penúltima sección.

El estudio comparado de la reclusión penal en los dos continentes se inicia con el análisis de seis dimensiones - relacionadas entre sí - de las instituciones correspondientes: la organización interna de los espacios, la vigilancia, el aislamiento, la supervisión, el control administrativo y la formalización. Esta secuencia no solamente facili- ta la exposición (porque una dimensión naturalmente conduce a la siguiente), sino que también tiene un significado analítico: las tres primeras dimensiones se refieren principalmente al aspecto físico de la institución penal; las tres últimas se refieren al aspecto social. El contenido de esta serie de comparaciones es, forzosamente, resumido y relativamente sencillo: no hay espacio para retratar con detalle la privación de la libertad en cada continente.

No obstante lo anterior, el ensamblaje de una comparación de este tipo constituye un reto, porque se busca un perfil general que trascienda las particularidades de uno u otro recinto penal o época. Los establecimientos penales pueden variar de manera significativa, tanto entre sí como de año en año. Y este reto se redobla al enfrentarse con la cantidad desigual de materiales de estudio para cada región. Las sociedades con abundantes recursos económicos (como las de América del Norte) producen una mayor cantidad de conocimientos que las sociedades de pocos recursos económicos (como las de América Latina) sea esto a través del gobierno, las universidades o los centros de investigación - y de ello no se escapan los estudios penológicos. Basta una comparación veloz de las páginas web producidas por las instituciones penales y las instancias académicas en cada región para confirmar esta situación bien conocida. ${ }^{2}$

Si las descripciones siguientes están acertadas, habrá poco nuevo sobre el caso latinoamericano para el lector que conoce bien esta región. Más interesante puede ser la descripción de los centros penales de América del Norte. Sin embargo,

También es importante reconocer la mayor atención prestada durante los últimos 50 años a las instituciones penales de América del Norte, en la medida en que éstas hayan cambiado de ubicación social, moviéndose "desde la periferia hacia el centro" de la sociedad (Jacobs, 1977, p. 6; ver también Gaucher y Lowman, 1998; Melossi y Lettiere, 1998). La mayor atención social sobre el recinto penal ha contribuido a la mayor recolección de datos sobre ello, por encima de lo que se esperaría del crecimiento general en los conocimientos producidos en la ciencia social norteamericana. En cambio, las instituciones penales de América Latina siguen ocupando un lugar marginal en la sociedad y solamente irrumpen en la conciencia pública cuando se trata de algún acontecimiento grave (como, por ejemplo, un motín o una fuga masiva). 
es únicamente a través de estas comparaciones básicas que las semejanzas y diferencias entre ambas regiones pueden establecerse. Posteriormente, las consideraciones sobre las diferentes dimensiones de los recintos penales se juntarán en una reflexión general sobre la naturaleza de la privación de la libertad en cada región. El planteamiento principal será que existen diferencias tanto cuantitativas como cualitativas entre América del Norte y América Latina, las cuales implican que se debe proceder con cierto cuidado a la hora de nombrar las instituciones penales en cada continente. ${ }^{3}$ Precisamente este es el argumento sutilmente planteado por la creatividad semántica de los investigadores que hablan de la "prisiónalmacén” y del "campo de concentración.” En la conclusión se identifican algunas líneas de investigación que ayudarían a esclarecer y explicar las diferencias encontradas.

\section{LA ORGANIZACIÓN FÍSICA DE LA PRIVACIÓN DE LA LIBERTAD: disposición espacial, vigilancia, aislamiento}

\section{Disposiciones espaciales}

La organización del espacio es relevante para los objetivos de la institución porque refleja y permite un determinado tipo de control. Una dimensión clave de la organización espacial es la clasificación de los reclusos, la cual tiene una larga historia en los sistemas penales (ver, por ejemplo, McCartney, 1933). En términos generales, la clasificación permite el agrupamiento de individuos similares con el objetivo de lograr algún propósito. En las instituciones penales, los criterios principales de clasificación se encuentran reflejados en los arreglos residenciales bajo los cuales los

\footnotetext{
${ }^{3}$ Por ello, en este trabajo, se hablará indistintamente de "instituciones de privación de la libertad", "establecimientos penales", o "recintos penales", para denotar los sitios donde se aglomeran a las personas sometidas a órdenes judiciales de detención. Las palabras "cárcel” (y su término correspondiente en inglés - jail), "prisión” (prison), "penitenciaría”, e "internado judicial”, solamente se emplearán al citar textos legislativos o académicos que las incluyan.
}

grupos de diferentes reclusos habitan determinados espacios o edificaciones. La clasificación también afecta las posibilidades de movimiento dentro de la institución, lo cual constituye otro aspecto importante del régimen espacial.

En América del Norte, los establecimientos penales reflejan un enfoque sistémico sobre la organización espacial. A un primer nivel, se ha establecido una distinción básica entre las jails ("cárceles"), utilizadas para la detención preventiva y las penas de corta duración, y las prisiones (destinadas a penas de mayor duración). En un segundo nivel, las prisiones están clasificadas en términos de su papel en relación con otros establecimientos de la misma jurisdicción y en términos de las características y usos de sus secciones internas. Los criterios empleados en el proceso de clasificación dependen de los objetivos asignados a las prisiones, los cuales han sido modificados en décadas recientes. Hasta mediados de los años 1970, se consideraba que el objetivo principal de la privación de la libertad era el tratamiento, y los diferentes establecimientos se organizaban según el tipo de programa que ofrecían; por ejemplo, el “....Centro de Rehabilitación de California, para los consumidores de drogas; la Prisión Médica de California en Vacaville, para los enfermos mentales; [y el] Instituto Vocacional Deuel, para los jóvenes adultos" (Feeley y Simon, 1992, p. 461). Sin embargo, la creciente desilusión con las posibilidades de lograr una rehabilitación exitosa del reo, junto con la mayor preocupación pública en cuanto al aumento de las tasas delictivas, produjo un cambio en la filosofía penal para privilegiar la "incapacitación”" (Garland, 2001). Bajo esta nueva perspectiva, el objetivo principal es el manejo del riesgo de delinquir o reincidir (Feeley y Simon, 1992). ${ }^{5}$ Ahora se organizan los establecimientos

${ }^{4}$ La incapacitación echa de lado las pretensiones del tratamiento o de la disuasión y pregona la segregación de los delincuentes convictos en instituciones penales para que estos no puedan cometer delitos contra el resto de la sociedad.

${ }^{5}$ Lo dicho aquí describe la evolución de la filosofía penal en Estados Unidos. El cambio del tratamiento hacia el castigo y la incapacitación fue mucho más atenuado en Canadá (Meyer y O’Malley, 2005). 
penales no por la función que cumplen sino por su nivel de "seguridad."

Las categorías básicas del sistema actual de clasificación son máxima, mediana y mínima seguridad y las características de cada renglón se ejemplifican muy bien en la siguiente descripción, proveniente del Departamento de "Correcciones" del estado de Carolina del Norte (EE.UU.) (ver NCDC, 2007):

El nivel de seguridad de la prisión es un indicador del grado en que el delincuente asignado a ese establecimiento se encuentra separado de la comunidad civil....Las prisiones de seguridad cerrada típicamente comprenden celdas individuales organizados en bloques, que pueden ocupar uno o varios edificios. Las puertas de las celdas generalmente son controladas por vía remota desde un puesto seguro de control... La valla externa comprende un diseño de doble cerca con torres para vigilantes armados o patrullas móviles de personal armado... Las prisiones de mediana seguridad típicamente comprenden dormitorios seguros que proporcionan el alojamiento para hasta cincuenta internos en cada uno... Cada dormitorio es cerrado en horas de la noche y un guardia se ocupa de la supervisión directa de los internos y del área del dormitorio... Estas prisiones normalmente tienen un perímetro de doble cerca con torres para vigilantes armados o patrullas móviles de personal armado... Las prisiones de seguridad mínima comprenden dormitorios no cerrados que son patrullados regularmente por guardias... Estas prisiones generalmente tienen uno sola cerca perimetral, la cual es revisada en forma regular pero no cuenta con torres para vigilantes armados ni patrullas.

Obviamente, la clasificación de los internos también requiere un espacio propio, sea este un establecimiento especializado o una unidad dentro de otra prisión, donde los delincuentes con condena firme cumplen las primeras semanas (o meses) de su condena mientras son evaluados en términos de los "riesgos" y las "necesidades" que presentan. Adicional a todo lo anterior, también se requiere una unidad de castigo, para poder disciplinar a los internos rebeldes o violentos. Esta unidad de castigo normalmente se conoce como la unidad, o prisión de "máxima seguridad" (o

${ }^{6}$ En Estados Unidos, el término "corrections“ es todavía muy común como designación del sector penal. Al comunicar una supuesta vocación de "corregir” al reo, esta palabra indicaría que se intenta modificar su conducta, bien sea mediante el tratamiento o la disuasión. Sin embargo, como hemos notado, actualmente la tendencia más fuerte en el sector penal estadounidense es hacia la incapacitación. "supermax" si el calificativo "máxima” ya ha sido asignado a una unidad de menor nivel de seguridad que éste). Nuevamente, el Departamento de Correcciones de Carolina del Norte ofrece una descripción típica de estos recintos:

Las unidades de seguridad máxima comprenden celdas con puertas rodadizas que se operan desde un puesto seguro de control... Estas unidades se destinan al encierro de los internos más peligrosos que constituyen una amenaza severa para la seguridad pública, el personal correccional y los demás internos. Los internos enviados a una unidad de seguridad máxima típicamente pasan 23 horas del día en sus celdas. Durante la hora restante posiblemente se les permite ducharse o tomar ejercicio dentro del mismo edificio o en un espacio externo enrejado. (NCDC, 2007)

La libertad de movimiento dentro de un establecimiento penal cualquiera se relaciona estrechamente con su nivel de seguridad: al nivel máximo, todo interno es sometido a medidas de sujeción física (esposas, cadenas, etc.) y trasladado con escolta; al nivel mediano, frecuentemente el interno necesita un pase para poder mover de una sección del establecimiento a otra, mientras que al nivel mínimo, los controles sobre el movimiento se restringen a ciertos espacios y horas del día.

En América Latina, hay normas que pautan la clasificación de los internos, pero el acatamiento de estas normas es muy variado. En general, la separación entre la detención preventiva (previa a la condena) y la privación de la libertad (después de la condena) es borrosa porque la organización de la planta física de los establecimientos penales no corresponde totalmente con las categorías legales de reo. Así, los cuerpos policiales cuentan con retenes, pero estos rara vez se equiparan a las cárceles policiales de América del Norte. El retén policial en América Latina se destina a las personas arrestadas durante las fases iniciales de un caso penal, pero aquellos con una medida de detención preventiva impuesta por un tribunal son enviados a otros establecimientos. La legislación penal concibe a estos últimos establecimientos en términos muy similares a las cárceles (jails) norteamericanas, pero, en la práctica, forman parte del sistema de "prisiones" y 
se emplean como tal. Por ejemplo, por mucho tiempo, en Venezuela, el Código Penal (Venezuela, 1964; 2005) y la Ley de Régimen Penitenciario (Venezuela, 1975; 2000) han distinguido entre las penitenciarías, con penas de presidio (celdas individuales, trabajos forzados); las cárceles nacionales, con penas de prisión (celdas o pabellones grupales, trabajos voluntariamente elegidos); las colonias móviles (para la realización de obras públicas o la práctica de la agricultura en zonas apartadas del país); y los internados judiciales (para la detención preventiva y el cumplimiento de penas no mayores de un año). Sin embargo, la materialización de este conjunto de establecimientos requeriría la construcción de un internado judicial en cada estado (porque los estados proporcionan las unidades geográficas de los circuitos penales), y de las penitenciarias, cárceles nacionales y colonias móviles en determinados puntos del territorio nacional para albergar a los reos con condenas mayores de un año. En la práctica, nunca se han destinado los recursos económicos necesarios a este sistema, de manera que la mayoría de los circuitos penales cuentan con un solo establecimiento penal que debe cumplir todas las funciones pautadas por la ley. Así, los “internados judiciales” albergan a reos con condenas mayores de un año mientras que las penitenciarías y las cárceles nacionales también sirven para la detención preventiva. Por lo demás, la diferencia entre "cárceles" y "penitenciarías" se aprecia parcialmente en el diseño arquitectónico de los respectivos establecimientos, pero no en sus regímenes internos - que son prácticamente iguales en todos. De modo similar al caso venezolano, en 1982, Ecuador promulgó una nueva legislación que designó los establecimientos penales como "Centros de Rehabilitación Social” y los clasificó en niveles máximo, mediano y mínimo de seguridad. Sin embargo, este sistema clasificatorio nunca llegó a implementarse (en parte, se adujo, por la falta recursos) y "Hoy, hay 36 Centros de Rehabilitación Social en condiciones físicas abominables, donde el único criterio de clasificación es el sexo del recluso." (del Olmo, 1998, p. 128). ${ }^{7}$

${ }^{7}$ Hace 30 años, Rico (1977) reportó una situación similar para toda América Latina.
Colombia ofrece una excepción parcial a esta tendencia, porque, durante los años 1990, inició un programa ambicioso de construcción de nuevos establecimientos de máxima seguridad para albergar a los jefes de la guerrilla y a los narcotraficantes. Sin embargo, estos establecimientos dependían de diseños y financiamiento estadounidenses y representaban solamente una parte de la planta física penal del país, si bien la parte de mayor perfil nacional e internacional (del Olmo, 1998). Lo excepcional de estos establecimientos subraya la tendencia general de los gobiernos latinoamericanos de no invertir (¿o no querer invertir?) en la construcción de planta física, aún de cara a niveles de hacinamiento medianamente altos (Carranza, 2001). ${ }^{8}$

La distinción entre la detención preventiva y la privación de la libertad como condena todavía podría mantenerse si los establecimientos penales fueran divididos internamente en unidades especializadas, pero ello no ocurre con frecuencia: los internos son ubicados dentro de la institución según su nivel social o región de procedencia (Aldana, 1972; Olivero, 1998). ${ }^{9}$ Como resultado, se entremezclan los internos de diferentes categorías legales (acusados, condenados), procesados por diferentes tipos de delito y con condenas de variada duración, lo cual hace que la población de internos en cualquier establecimiento

${ }^{8}$ Según cifras presentadas por Carranza (2001), el nivel promedio del hacinamiento en América Latina (el número de internos expresado como porcentaje de la capacidad oficialmente designada de cada establecimiento) era $148 \%$ en 1999 . Esta cifra se puede comparar con los siguientes datos para Estados Unidos: establecimientos del Buró Federal de Prisiones - 134\%, establecimientos de los departamentos de prisiones (o correcciones) en cada estado - $101 \%$, establecimientos privados - 89\% (BJS, 2003), y cárceles de condado (retenes policiales) - 93\% (BJS, 2001). En Canadá, un informe del gobierno federal comenta que "en muchas jurisdicciones, el número de adultos encarcelados ha llegado cerca de la capacidad institucional en años recientes" (Juristat, 2006, p. 19), de lo cual se infiere que el hacinamiento todavía no existe en ese país aunque podría manifestarse en el futuro.

${ }^{9}$ Las unidades para la clasificación de los internos son poco comunes en los establecimientos penales de América Latina y, donde existen, tienden a convertirse en refugios de los profesionales adeptos del positivismo italiano. Por ejemplo, todavía en 1984, un especialista ecuatoriano escribía sobre la clasificación biotipológica de los delincuentes, la cual incluía el delincuente "normal", el "inducido", el "no adaptado", el "hiperevolutivo" y el sicópata (Narváez, 1984). 
penal de América Latina sea mucho más heterogénea (en términos de estas características) que en América del Norte. ${ }^{10}$ Por otra parte, la ausencia de grandes diferencias entre los establecimientos penales en América Latina hace que la noción de un sistema penal, con unidades de distintas características articuladas entre sí, sea más débil que en América del Norte. En términos generales, el establecimiento penal latinoamericano se aproxima al establecimiento de mediana seguridad en Norteamérica.

\section{La vigilancia}

La vigilancia de los internos depende de la presencia física de personal de guardia en el recinto, auxiliada por cualquier recurso tecnológico que esté disponible. El Cuadro 1 presenta información sobre la relación entre el número de internos y el número de personal de control en Canadá, Estados Unidos, y varios países latinoamericanos. Aunque estas cifras contienen errores internos derivados de las diferentes maneras de definir y contar el personal de control, el patrón general indica una mayor cantidad de internos por cada miembro del personal en América Latina que en América del Norte. De modo similar, en una comparación detallada de una cárcel estadounidense y un internado judicial venezolano, Jordan (1996) encontró que el establecimiento estadounidense contaba, en promedio, con un guardia por cada cinco internos, mientras que en el establecimiento venezolano se contaba con un guardia por cada 17 internos. En términos de la cantidad de guardias específicamente trabajando en cada turno, la relación guardia/interno era 1:23 y 1:65, respectivamente.

Como es de esperar, para incrementar la capacidad de observación los establecimientos penales en América del Norte, también se incorporan, de modo regular, las tecnologías de vigilancia, en especial los detectores de metales y la televisión de circuito cerrado. En este sentido, la siguiente descripción de una cárcel de 186 “camas", ${ }^{11}$ recién inaugurada en el Estado de Nueva York, ilustra el futuro probable de la vigilancia tecnológica:

... el sistema integrado de seguridad electrónica del establecimiento [...] incluía cinco estaciones de control computarizado con pantalla táctil, tres paneles gráficos, 260 puertas controladas y monitoreadas, 165 estaciones de intercomunicadores, 165 lectores de tarjetas de proximidad y más de 110 cámaras [...] Con la instalación de [un] sistema de seguridad electrónica, el establecimiento puede incrementar significativamente su capacidad de vigilar a los internos. El diseño intuitivo y flexible de las pantallas táctiles, junto con la facilidad de su

Cuadro 1 - Relación de internos a personal de control en varios paísesde regressão logística para investimentos educacionais, 1999-2002

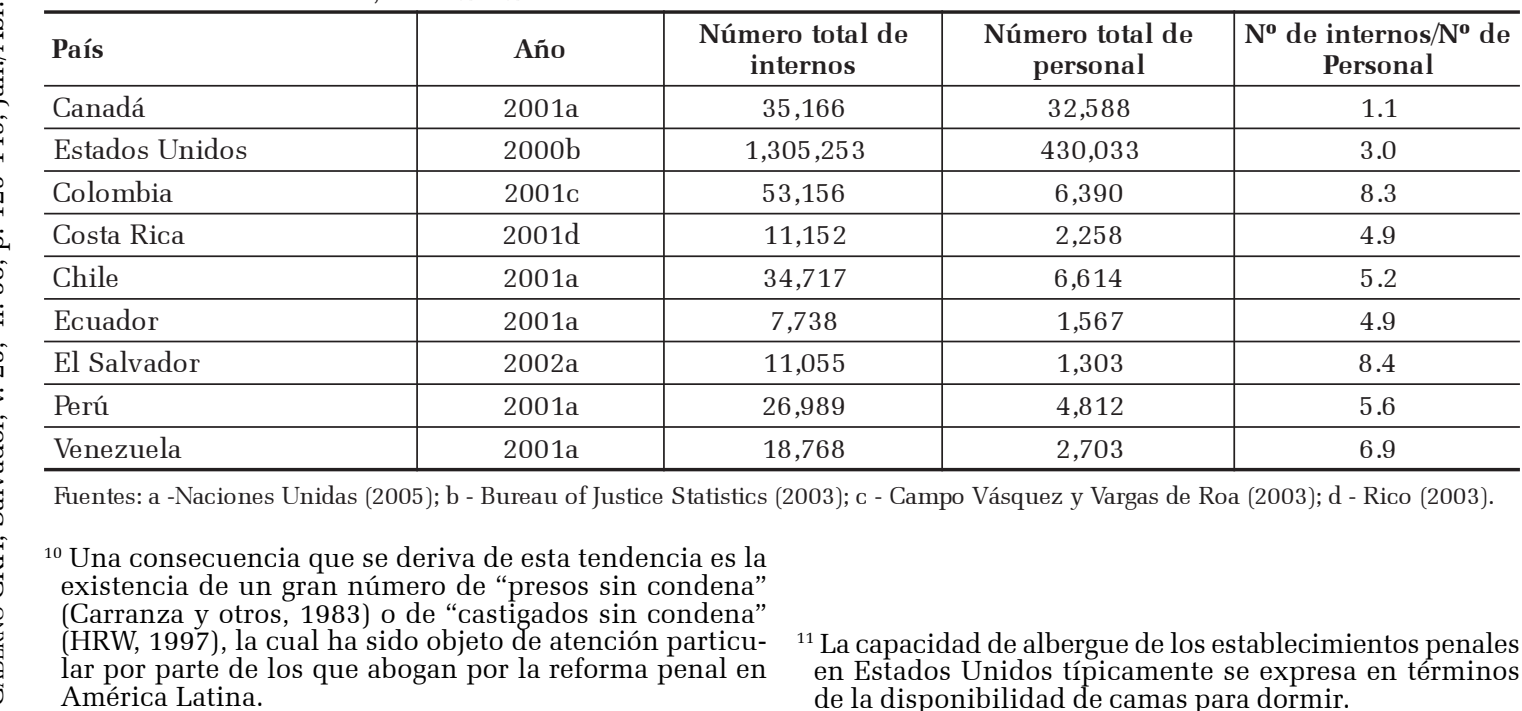


configuración, permite que un vigilante pueda observar la actividad de 42 internos comparado con la capacidad original de 24. (Werner, 2006)

Adicionalmente, varios "sistemas de seguimiento de los internos" han sido desarrollados, basados en pulseras electrónicas. La publicidad para uno de estos sistemas menciona los siguientes beneficios:

El sistema de gerencia de prisiones RFID ${ }^{12}$ tiene tres funciones. Evita que los internos se fuguen, ya que suena una alarma si el interno con la pulsera se aproxima al perímetro del establecimiento; reduce la violencia, porque permite al personal de guardia monitorear quién se asocia con quién; y facilita las tareas administrativas al poder localizar a un interno cuando sea necesario. (Swedberg, 2005)

Obviamente, como los países latinoamericanos tienen recursos mucho menores, la vigilancia tecnológica está casi ausente por completo. Esta situación, aunado al menor número de personal de vigilancia, significa que el nivel de supervisión y monitoreo de los internos sea mucho menor en América Latina que en América del Norte.

\section{El aislamiento}

El grado de aislamiento de los internos del resto de la sociedad depende de las normas que reglamentan las visitas, el uso de teléfonos, y la disponibilidad de televisores, entre otros. En América del Norte, la frecuencia y modalidad de visita generalmente varían según el nivel de seguridad del establecimiento. Los internos sometidos a máxima seguridad solamente pueden tener visitas sin contacto físico, esto es, visitas realizadas en cubículos con vidrios que separen al interno y su visitante y con comunicación por vía telefónica. Adicionalmente, se restringe el número de visitas y éstas duran menos que en otros establecimientos. Los internos asignados a seguridad mediana o mínima tienen el derecho a visitas con contacto físico (en una sala o patio con

${ }^{12}$ RFID son las siglas en inglés para "Radio Frequency Identification Technology” (Tecnología de Identificación Basada en Frecuencia Radial) presencia de personal de guardia) y pueden disfrutar de un mayor número de visitas, cada una con mayor duración. También se permiten las visitas "familiares" (o conyugales) para los internos en estos establecimientos (ver, por ejemplo, CSC, 2007a).

El nivel de control ejercido sobre las visitas y los visitantes es considerable. Los internos deben solicitar autorización previa para cada visitante y éste debe acatar las normas sobre vestimenta aceptable (Comfort, 2003), mientras que el comportamiento en el salón de visitas debe minimizar el contacto físico:

A los internos y sus visitantes, se les permite un breve abrazo y beso al inicio y final de la visita. Un interno puede cargar a su(s) hijo(s) menor(es)[...].Se permite al interno y su visitante tocar las manos por encima de la mesa y a plena vista, sin otro contacto físico. El contacto excesivo (besos, masajes, caricias, y el sentarse sobre las piernas o con las piernas entrecruzadas) podría ocasionar la terminación de la visita (CDCR, 2007, p. 9).

Esto, por lo menos, es lo que pautan las autoridades.

En América Latina, las normas en cuanto a visitas son mucho más permisivas. Típicamente, hay uno o dos días de visita en cada semana, durante los cuales se permite el acceso de los familiares y amigos de todos los internos, con excepción de los que están en segregación administrativa o celdas de castigo. La administración del penal no mantiene, ni requiere, listas de las personas autorizadas a entrar, pero cualquier visitante debe saber el nombre del interno que va a visitar, portar identificación, acatar las normas sobre vestimenta y someterse a una requisa si esta es practicada. Generalmente, el período de la visita es de cuatro a seis horas, y no hay áreas específicamente designadas para el encuentro entre internos y visitantes, ni supervisión de su contacto. Por ejemplo, en Brasil:

Pocos establecimientos penales cuentan con áreas especiales para las visitas; al contrario, frecuentemente se permite a los visitantes ingresar directamente a las áreas de habitación de los internos. En algunas prisiones, como la 
Casa de Detenção de Sao Paulo, las "visitas sociales" con la familia y los amigos se realizan en el patio, mientras que a las esposas y novias se les permite ingresar a las celdas. (HRW, 1998, p. 115)

La mayoría de los internos tienen derecho a las visitas conyugales con cierta frecuencia e independiente de su estado civil (Olivero, 1998). En algunos casos, los establecimientos son visitados por prostitutas para cumplir citas previamente concertadas con los internos (HRW 1997; 1998).

Los que escriben sobre los establecimientos penales latinoamericanos concuerdan en que estos se transforman durante la visita. Por ejemplo, MacNeil comentó lo siguiente sobre un establecimiento penal venezolano:

Después de tres días en la prisión, tuve mi primera experiencia del día de visita. El ambiente de la prisión se transformó completamente al ingresar multitudes de mujeres y niños al patio, cargadas con bolsas de alimentos, y por unas pocas horas, la institución completa presentó un aspecto de gala. ${ }^{13}$

Oliveira (1998, p. 104) describe una situación similar en México:

En algunos establecimientos, se les permite a familias enteras vivir con sus seres amados tras los muros por períodos largos. Es común ver a niños correr y jugar en las prisiones mexicanas.

Si bien las visitas reflejan la importancia de la familia en la cultura latinoamericana y ofrecen un escape del aburrimiento y la violencia de la vida institucional, es importante reconocer su papel en facilitar el acceso externo al mundo penal. Una o dos veces por semana, el establecimiento se convierte en un espacio donde se entremezclan los visitantes y casi todos los internos (ya que los internos sin visitantes pueden pasar tiempo con aquellos que visitan a sus compañeros, o vender comida o artesanía a todos los que llegan de afuera). Estas posibilidades rompen significativamente el aislamiento que, de otra manera, se experimentaría

${ }^{13}$ Otro interno británico asignado al mismo establecimiento tuvo una impresión similar: Los visitantes llegaron a las nueve, y yo pasé el resto del día con Paul mientras que, afuera, deambulaban las parejas, jugaron niños de todas las edades y un ambiente general de fiesta se adueñó de lugar (Kane y Tilsley, 2006, p. 88)
Adicionalmente, la relativa libertad concedida a los internos y visitantes en cuanto a movimiento y actividades en el recinto durante el horario de visita difiere considerablemente del control cercano que típicamente se observa en los establecimientos penales de América del Norte y constituye un reconocimiento tácito de que el interior del penal latinoamericano no pertenece a las autoridades sino a los internos.

\section{LA ORGANIZACIÓN SOCIAL: el control de los internos, la responsabilidad administrativa y la formación de las normas}

\section{El control de los internos}

Los establecimientos penales ofrecen un buen ejemplo del concepto de institución total ideado por Goffman ([1961]1991), donde se observa una clara división entre un pequeño grupo de personal de supervisión y un gran grupo de internos sometido a su control. Sin embargo, las instituciones totales varían en términos del nivel de supervisión por parte del personal institucional y el nivel de auto-regulación.

En América del Norte, todo apunta hacia una disminución, a través del tiempo, en la participación de los internos en la organización y supervisión del establecimiento. Por ejemplo, Jacobs (1977) encontró que, en los años 1930, gran parte del trabajo administrativo en la Penitenciaría de Stateville (Estado de Illinois) estuvo a cargo de los internos. Esta situación duró hasta los años 1960, cuando empleados civiles reemplazaron a los internos. En otros establecimientos, algunos internos se encargaban de la vigilancia, como, por ejemplo, los “internos-guardias" que supervisaban a otros internos en los cultivos de caña de azúcar pertenecientes a la Penitenciaría de Angola (Estado de Louisiana) (Rideau y Wikberg, 1992). Todavía en otros establecimientos, los internos se encargaban de la vigilancia de los dormitorios, como es el muy conocido caso de los building tenders (encargados de pabellón) quienes, hasta los 
años 1970, vigilaban los bloques residenciales en el sistema penal del Estado de Texas (Marquart y Crouch, 1984; 1985). Estos y otros papeles, como el de informante (ver, por ejemplo, Colvin, 1992), forjaron lazos estrechos entre el personal institucional y los internos en la regulación interna del establecimiento.

Debido a varios factores, producto de la mirada externa cada vez más fuerte sobre los establecimientos penales en América del Norte, estas estructuras de poder y autoridad han desvanecido casi por completo. Actualmente, la participación de los internos en la vigilancia o administración del penal es escasa o nula, salvo en el área de programas educativos y de tratamiento (ver, por ejemplo, Díaz-Cotto, 1996). Aun aquí, las posibilidades son limitadas. Por ejemplo, al catalogar once establecimientos penales estadales según la tipología de regulación interna propuesta por Dilulio (control, responsabilidad, consenso), Reisig (1998) encontró solamente dos establecimientos que correspondían al modelo de responsabilidad (el cual permite un mayor nivel de participación de los internos en los asuntos institucionales).

Una consecuencia de esta tendencia a excluirlos de las actividades administrativas y de custodia es la mayor nivelación de los internos, ya que ahora tienen menores posibilidades de obtener poder o influencias dentro de la administración. Si bien las pandillas y bandas actualmente constituyen una estrategia importante de organización social de los internos (Gaes y otros, 2002), la cual reproduce parcialmente las jerarquías y estilos de control que poseían los internosguardianes y los encargados de pabellón, a diferencia de estos las pandillas no son promovidas por la administración del penal ni se consideran mecanismos apropiados para la regulación interna. En consecuencia, la actitud de los guardias hacia las pandillas puede ser de rechazo o tolerancia, pero nunca de aceptación. Eliminada la posibilidad de incorporar formalmente a los internos a la estructura de control institucional, las autoridades han optado por diferentes medidas: aumentar la cantidad de guardias; incrementar las restricciones y el control sobre el movimiento de los internos; aumentar la vigilancia; buscar algún equilibrio entre las diferentes pandillas; o simplemente hacer caso omiso de cualquier problema de orden interno, salvo los más graves.

En América Latina, el uso de algún tipo de encargado de pabellón o bloque residencial parece ser común y data de tiempo atrás. Por ejemplo, Aguirre (2005, p. 150) encontró que el reglamento interno de la Penitenciaría de Lima, en 1901, pautaba el nombramiento de un caporal para cada sección y de un caporal mayor “...para asegurar que los encargados del orden y limpieza dentro de la prisión cumplieran con su tarea; también para reportar cualquier cosa que ocurriera adentro. Aldana (1972, p. 54) describió el delegado de pabellón en el Retén de Catia (en Caracas) donde fue encarcelado ("un procesado a quienes [sic] las autoridades del Retén le reconocen buena conducta y capacidad para llevar el control interno de cada Pabellón”), y del mismo modo, mas o menos para la misma fecha, Bayer (1978) escribió sobre los jefes de patio o pasillo en un establecimiento penal de Bogotá. Más recientemente, la organización nogubernamental Human Rights Watch (1977) encontró que los delegados de pabellón en el Retén de Catia ahora se llamaban "polipresos", mientras que MacNeil encontró un sistema bien desarrollado de control por parte de los internos (con anuencia institucional) en la Penitenciaría de Occidente en Venezuela. ${ }^{14}$

Sin embargo, previo a su estadía en esa penitenciaría, MacNeil había estado en otro establecimiento penal venezolano donde no existía una alianza estratégica entre el personal institucional y los internos, ni intento alguno de

${ }^{14}$ Nos presentaron al 'cabo' o jefe de la letra [dormitorio], y empezamos a comprender algo sobre la organización de la prisión. Había el típico equipo gerencial de hombres duros que mandaban dentro de la prisión, pero estos, al igual que todos los demás miembros de la organización de internos, jugaban un papel doble. Para los reclusos, representaban el 'gremio', o gerencia, y constituían la ley dentro de la prisión, con poder de vida y muerte sobre estos [...] Sin embargo, para las autoridades de la prisión, se conocían como el comité de internos, y se reunían regularmente con el director y otros oficiales para organizar campeonatos deportivos, eventos culturales, cursos educativos y otros aspectos de la vida de la prisión. (MacNeil, 2006, p. 200; ver también Marquart y Crouch, 1985). 
reemplazar ese tipo de control por una presencia oficial más permanente e intrusiva. Los vigilantes se limitaban a controlar al paso por ciertas puertas y rejas, a intentar imponer algún orden en las colas para recibir la comida, y a evacuar los internos enfermos, heridos o muertos. Human Rights Watch encontró una situación similar en algunos establecimientos penales brasileños. Por ejemplo, en la Penitenciaría João Chaves de Natal, que contaba con 646 internos, solamente había tres vigilantes durante el día en que esta ONG hizo su visita:

...los tres vigilantes permanecieron en una mesa cerca de la entrada de la prisión. Durante el día [que pasamos] en el establecimiento, rara vez vimos que se levantaran de la mesa para monitorear la situación de la población interna. (HRW, 1998, p. 71).

Cuando el personal de guardia renuncia a casi toda tentativa por mantener el control interno, las relaciones entre los reclusos rápidamente pueden volverse conflictivas y violentas (Hidalgo y Jordan, 1993-1994), con treguas establecidas únicamente durante las horas de visita. Por su tendencia a generar periódicas guerras internas (con un gran saldo de heridos y muertes ${ }^{15}$ ), esta forma de auto-regulación ejercida por los presos, basada en la anarquía, es más problemática - por ser más violenta todavía que el co-gobierno establecido entre las autoridades del penal y los delegados de pabellón. Estos dos tipos de regulación interna emergen y decaen en diferentes épocas y regiones en el continente latinoamericano, proporcionando un contraste muy marcado con las estructuras de poder en los establecimientos penales norteamericanos.

${ }^{15}$ Cuando no se logre mantener a las diversas bandas aisladas unas de otras, los enfrentamientos pueden generar una gran cantidad de muertos, como en el caso de la Cárcel Nacional de Sabaneta, en Maracaibo, Venezuela, donde fallecieron más de 100 internos en un enfrentamiento protagonizado durante varias horas en enero de 1994 (HRW, 1994). Adicionalmente, este tipo de auto-regulación entre los internos conlleva políticas de contención y control militares por parte de las autoridades, las cuales ofrecen oportunidades para la violencia del estado y la violación de derechos humanos. Quizás el ejemplo más preocupante de este problema se evidenció en octubre de 1992 en la toma militar de la Casa de Detenção de Carandiru en São Paulo, Brasil, después de una reyerta. La mayoría de las muertes de 111 reclusos se atribuye a la actuación de las fuerzas militares y no a la violencia entre los propios internos.

\section{La responsabilidad administrativa}

La desaparición de los "internos-guardias" en los establecimientos penales de América Norte fue, con toda probabilidad, paulatina; empero, su fin fue sellado por la intervención de los tribunales federales en los asuntos internos del "sistema correccional”. Desde los años 1960, los presos en América del Norte habían estado organizándose para exigir mejoras en el trato, y, en esta lucha, fueron auxiliados por los grupos extra-muros trabajando a favor de los derechos del recluso (Irwin, 1980). Una estrategia importante en esta campaña fue la introducción de pleitos judiciales para dar publicidad al trato inhumano de los internos y a la arbitrariedad de muchas decisiones importantes para la trayectoria penal del reo (como por ejemplo, la redención de la pena por buena conducta, las salidas temporales y la libertad condicional) y a la vez buscar soluciones para estos problemas. En muchos casos importantes, los tribunales federales emitieron fallos que obligaron a los departamentos de prisiones a llegar a un acuerdo con los demandantes sobre las mejoras que se introducirían en los establecimientos penales y sobre un cronograma para lograrlo. Adicional a ello, algunos fallos se ocuparon de exigir mayores garantías procesales para los internos a la hora de decidir sobre casos de redención de la pena y de mala conducta (Feeley y Rubin, 1999). En Canadá, han sido los comités de investigación e interpelación, nombrados por el gobierno, que han asumido el papel jugado por los tribunales en Estados Unidos. La creación de estos comités frecuentemente responde a alguna crisis en el sistema penal, y sus informes finales están repletos de críticas sobre el trato inhumano y arbitrario de los internos, y de propuestas para la reforma (Gaucher y Lowman, 1998).

Los tribunales estadounidenses y los comités de investigación canadienses reflejaron una tendencia, en América del Norte, de incorporar a los presos a la "sociedad de masas" (con los mismos derechos que los demás ciudadanos) y de mirar con cada vez mayor detenimiento lo que pasa al 
interior de los establecimientos penales (Jacobs, 1977; Shils, 1962). Otro conjunto de observadores externos lo conformaron los políticos y el público en general quienes, al preocuparse por los aumentos en la criminalidad a partir de los años 1960, se aliaron para exigir mayor vigilancia y control del reo en vez de su tratamiento (Garland, 2001). Parece que esta tendencia ha sido más marcada en Estados Unidos (Melossi y Lettiere, 1998) que en Canadá (Moore y Hannah-Moffatt, 2005), y, en la medida en que se haya traducido en cambios concretos, estos apuntan hacia una mayor preocupación por la seguridad (entendida como el intento de reducir las conductas problemáticas entre los internos).

La confluencia de estas demandas externas sobre el control penal se aprecia en el lema de el Servicio Correccional Canadiense - "Seguridad, Respeto y Dignidad para Todos” (CSC, 2007b) - y ha llevado al intento consciente de lograr un “equilibrio" (Meyer y O’Malley, 2005) entre estos objetivos, que fácilmente pueden contraponerse. Sin embargo, una consecuencia de estos cambios es que ha sido parcialmente atenuado el "principio de menor elegibilidad", que, en el ámbito penal, exige que los presos vivan en condiciones materiales por debajo de aquellas con que cuentan los estratos más pobres de la sociedad. ${ }^{16}$

En América Latina, también se ha visto el vuelco hacia políticas más punitivas, pero, a diferencia del Norte, no se ha observado la contratendencia hacia una privación de la libertad más humanitaria. El aumento rápido en las tasas

${ }^{16}$ Cuando se ha hecho muy insistente el reclamo público para mayores niveles de castigo en el sistema penal, algunos de los "lujos" de la vida institucional (el gimnasio, la televisión, etc.) han sido temporalmente suprimidos. No obstante, es indudable que las condiciones materiales en los establecimientos penales de Norteamérica ya han superado aquellas que caracterizan a los segmentos más pobres de la sociedad: El personal de la prisión debe administrar los servicios y programas para una población interna cada vez más diversificada. El personal debe tomar en cuenta el nivel de iluminación, el consumo calorífico, la temperatura de las comidas, las necesidades recreativas, el tamaño de las celdas y la densidad poblacional, la composición étnica y racial de las zonas habitacionales y las celdas, los requisitos disciplinarios y la seguridad personal, la salud, las necesidades en cuanto a correo y correspondencia, las necesidades higiénicas, y una multitud de otros asuntos, cada día y cada hora (Marquart, 2005). delictivas desde los años 1980 ha generado niveles históricamente altos de preocupación en cuanto a la delincuencia y la seguridad personal (Caldeira, 2000; Rotker, 2000), los cuales, a su vez, han sido un estímulo fuerte hacia la prevención del delito por cuenta propia, con el cierre de calles al paso libre, la instalación de rejas y alarmas y la contratación de vigilantes para la seguridad privada. También se observa un endurecimiento en las actitudes hacia el delincuente (Briceño-León, Camardiel y Ávila, 2006), y el tomar la justicia en manos propias ha llegado a la pena de muerte extrajudicial, bien en la forma esporádica de los linchamientos (Godoy, 2006), o de manera más organizada en los escuadrones de la muerte (Perea, 2003; Huggins y Mesquita, 1995). En este clima social, son pocas las posibilidades de mirar con detenimiento lo que ocurre al interior de los establecimientos penales o de mejorar el trato hacia el recluso.

Los establecimientos penales de América Latina siempre han captado la atención de por los menos algunos empresarios morales, sean estos filántropos adinerados (Aguirre, 2005), grupos de religiosos (Miller, 1998), académicos (por ejemplo, Córdova, 1999) o, más recientemente, los grupos de derechos humanos (por ejemplo, HRW, 1997; HRW, 1998). Estos han hecho mucho para dar a conocer y criticar fuertemente la situación interna de los establecimientos penales. Adicionalmente, los propios reclusos han recurrido a cartas al público, algunos libros y, sobre todo, protestas y huelgas para llamar la atención sobre las duras condiciones en que se cumple la privación de la libertad. Sin embargo, estas iniciativas no han sido lo suficientes para lograr un cambio importante y sostenido en el lugar que ocupan los establecimientos penales, y los que allí habitan, relativo al resto de la sociedad. Una de las dificultades particulares radica en la ausencia, casi por completo, de organizaciones que agrupan o trabajan a favor de los internos en el planteamiento de sus problemas: el preso típico cuenta con poca educación y capital social. Esta situación solamente cambia cuando se priva de la libertad a figuras políticas de importancia, ya que estas tienen una motivación 
especial (y las habilidades discursivas necesarias) para dar publicidad a los problemas penales (Aguirre, 2005; del Olmo, 1998). De vez en cuando, un gobierno decide decretar nuevas y mejores condiciones para los internos, como el gobierno populista de Juan Perón en la Argentina de los años 1950 (Caimari, 2004), pero estos cambios rara vez han significado más que retórica, ni han durado más que el gobierno correspondiente.

Otro obstáculo para el movimiento humanitario ha sido la renuencia de los tribunales a involucrarse en asuntos relacionados con los establecimientos penales. ${ }^{17}$ La respuesta legal y judicial a la crisis penal en América Latina ha sido el intento por reducir el uso de la detención preventiva a través de la reforma de las normas procesales (Vogler, 2005; Tocora, 2005), en vez de ocuparse directamente de los problemas en los establecimientos penales. Estos últimos son menos visibles aún para las instancias gubernamentales y el público en América Latina que sus contrapartes en América del Norte.

\section{La formalización de las normas}

La mirada crítica externa forma parte de una tendencia legal y burocrática más amplia en Norteamérica hacia una mayor responsabilidad administrativa. El personal administrativo y de vigilancia en los establecimientos penales se encuentra cada vez más susceptible de ser llamado a rendir cuentas ante sus superiores en el ejecutivo, o ante las asambleas legislativas, los tribunales, o la prensa (Riveland, 1999). A su vez, la mayor responsabilización administrativa ha contribuido a la codificación de las normas y del uso de documentos escritos como parte de una cultura de auditoría y control. Basta con revisar las páginas web de los departamentos de correcciones, y de los organismos que velan por el cumplimiento de las normas, para constatar esta situación. Por ejemplo, el Servicio Correccional de Canadá cuenta ${ }^{17}$ Hay, sin embargo, casos aislados de jueces que ordenan el cierre de establecimientos específicos, por ejemplo en Brasil (HRW, 1998,p. 19) y Venezuela (Martínez, 1993-1994). con casi 140 "Directivos del Comisionado” y nueve “Guías de Operación Estandarizada” (CSC, 2007c), mientras que el Buró Federal de Prisiones (BFP) en Estados Unidos tiene más de 280 documentos que detallan aspectos diferentes de la política penal (BOP, 2007). Entre estos, se hallan disposiciones sobre temas tan variados como la recepción de donativos, la premiación a los empleados, la apariencia de los internos y las pruebas que se deben efectuar al mobiliario. El sabor de este estilo de administración se capta muy bien en una declaración que, en 2006, el Director del BFP hizo ante la Comisión de Prisiones de Estados Unidos:

Más allá de la supervisión y revisión pautadas por instancias externas, el Buró es una agencia que se conduce de acuerdo a políticas con numerosos mecanismos internos de auto-evaluación crítica de control gerencial [...].El sistema primario de control en el Buró de Prisiones es el proceso de revisión de programas [...].Dos ejemplos tomados de las pautas para los Servicios Alimentarios institucionales sirven de ejemplo a continuación:

- "Revisar la documentación durante los últimos 6 meses para determinar si las clases sobre eficiencia en el trabajo (las charlas de seguridad mensuales) se están realizando y si los temas incluyen la instrucción sobre equipos específicos para este trabajo, materiales peligrosos, seguridad y procedimientos sanitarios.

- Determinar mediante observación directa si se han instituido los procedimientos de seguridad y si hay un uso apropiado de todos los equipos de seguridad y protección (donde estos sean pertinentes a la tarea) en el área de trabajo de los internos (por ejemplo, protectores para la maquinaria y los ojos, zapatos de seguridad, extinguidores de incendios cargados y funcionando, y estaciones operativas para el lavado de los ojos)."

En apoyo de este proceso de revisión, departamentos específicos de la institución realizan auditorías constantes a fin de asegurar que se estén llevando a cabo las acciones pautadas en los reglamentos correspondientes. Por ejemplo, puede que se efectúe una auditoría mediante la inspección de los registros de visitas en la Unidad Especial de Alojamiento, para asegurar que los empleados ejecutivos, los jefes de departamento y un psicólogo de la institución hayan realizado las rondas correspondientes y que los lugartenientes de turno estén realizando rondas durante cada turno. (Lappin, 2006, p. 5-7).

El significado de estas nuevas prácticas administrativas para el personal institucional es muy directo y evidente: 
Es un nuevo día. Cuando yo empecé por primera vez con el departamento, había muy poca documentación. Si se encerraba a un interno en su celda, eso se reportaba verbalmente al capitán de turno. En aquel entonces, no se preparaba un informe escrito como lo hacemos ahora [...].En los tiempos anteriores, se contaba con lo que llamábamos un manual. Ahora gerenciamos mediante los estándares y las políticas. No se nos permiten errores. Es importante que los guardias mantengan un dominio sobre las reglas y los reglamentos. Es importante que mantengan un dominio sobre los procedimientos operativos estandarizados y es importante que mantengan su dominio sobre los memoranda administrativos que emanan del departamento, la división o la oficina del director. (Beck, 2006, p. 2)

Ese estilo gerencial no se observa en los establecimientos penales latinoamericanos, donde las políticas de control y operación se materializan en textos legislativos. La mayoría de los países cuenta con un código penal y una ley del sistema "penitenciario", más algunos reglamentos (también emanados de la legislatura) y decretos ministeriales. Por ejemplo, Argentina cuenta con cinco reglamentos que acompañan la Ley Orgánica del Servicio Penitenciario Federal (SPFA, 2007), mientras que Colombia - un país que ha tenido mayor vocación normativa en el sector penal cuenta con, por lo menos, 40 decretos presidenciales o ministeriales que desarrollan o modifican la Ley 65 de 1993 (la columna vertebral legislativa de su sistema penal) (ver INPEC, 2007). Sin embargo, ningún país de la región evidencia el nivel de codificación normativa o control administrativo que se observa en América del Norte.

Las pautas legislativas, a veces tildadas de "brillantes" y "bien acabadas" ${ }^{18}$, coexisten con una preferencia, en los establecimientos penales, por un control ejercido a través de las instrucciones verbales (Jordan, 1996). El trabajo administrativo se ancla fuertemente en la inercia y en las tradiciones institucionales, mientras que la documentación es relativamente escasa. De allí se derivan dos consecuencias. La primera es que se recolecta poca información sobre los establecimientos penales, lo cual enfatiza su opacidad frente a la mirada públi-

18 "Estos códigos [penales] han sido descritos como 'brillantes' y 'bien acabados', lo cual es una manera elegante de indicar que casi nunca guían lo que ocurre en las prisiones" (Teeters, 1946, p. 24). ca. En casos extremos, es posible que ni siquiera exista un conteo preciso de la cantidad de internos albergados en la institución (ver, por ejemplo, Hidalgo y Jordan, 1993-1994). La segunda es que la especificación y el control de los procedimientos operacionales pueden ser marcadamente generales, de manera que los resultados de estos puedan variar mucho de institución a institución..$^{19}$ Normalmente, el desarrollo y la codificación de las reglas promueven un espíritu universalista en cualquier burocracia, y donde esto no ocurre puede que los modos típicos de actuar sean más particularistas.

Prueba de esta última tendencia sería la reproducción, en los establecimientos penales latinoamericanos, de las desigualdades sociales que se observan en la sociedad. Basta leer los comentarios de numerosos observadores quienes comparan el lujo relativo de las áreas ocupadas por los internos adinerados y los dormitorios paupérrimos ocupados por los internos pobres (Bayer, 1978; Bretas, 1996; Olivero, 1998). ${ }^{20}$

Un fenómeno vinculado al particularismo es la corrupción, cuya presencia en los establecimientos penales latinoamericanos es frecuentemente comentada (ver, por ejemplo, del Olmo, 1998; HRW, 1997; HRW, 1998). Sin embargo, hay que evitar las generalizaciones amplias y estereotipadas. Por ejemplo, Olivero (1998, p. 103) adujo que "Los presos [en México] tienen libertad casi absoluta de ingresar cualquier cosa al establecimiento, siempre y cuando se pague por ello a la administración de la prisión o se comparten los artículos en cuestión con los guardias". No obstante la afirmación anterior, otra imagen emerge de los únicos datos sistemáticamente recopilados sobre los pagos y sobornos en los establecimientos penales mexicanos. Basado en una encuesta a 1.600 internos, Bergman (2004, p. 13) encontró que la proporción de internos cuyos familiares tuvieron que pagar para bienes o servicios variaba entre $14 \%$

19 Esta tendencia se acentúa cuando el personal es enganchado sin entrenamiento previo para el trabajo.

${ }^{20}$ La organización de la vida al interior de las prisiones mexicanas es un espejo de la Sociedad Mexicana. O sea, hay claras distinciones económicas y de clase social. Para aquellos que tengan capacidad de pago, las comodidades son comprables. (Olivero, 1998, p. 103) 
(para las visitas conyugales) y 35\% (para sacar al interno a un salón de visitas). Puede ser que los establecimientos penales latinoamericanos sean particularistas; empero, no representan regímenes totalmente patrimoniales.

\section{ENCARCELAMIENTO E INTERNAMIENTO}

Según Irwin (2004), quien se refiere al concepto con mayor frecuencia que otros investigadores, la materialización de la “prisión-almacén” obedecea una mayor tendencia punitiva en el público norteamericano que se observó en esa región, entre las décadas de 1970 y 1990. En este tipo de establecimientos, prevalecen los objetivos de seguridad, eficiencia y economía. La importancia de la seguridad se refleja en la preferencia por pabellones y edificios relativamente pequeños (que facilitan el control de los internos), ${ }^{21}$ mientras que "[l]as celdas tienen ventanas exteriores extremadamentepequeñas, y su portada interior es maciza en vez de enrejada para evitar la posibilidad de que se arrojen objetos hacia el pasillo o que se empleen armas para agredir a quien transite por allí.” (Irwin, 2004, p. 59). La eficiencia se refleja en el uso de dispositivos electrónicos y centros de operación computarizados, cuyo objetivo es controlar los movimientos de los internos con "un mínimo de personal y un máximo de protección para éste.” (Irwin, 2004, p. 59). Finalmente, la economía se observa en la construcción sencilla y poco estética (con unidades de cemento prefabricado) y patios monótonos de asfalto, cemento o tierra. En estos establecimientos, el objetivo primordial es el confinamiento, más que el tratamiento y la rehabilitación. Si bien Irwin reconoce la existencia de programas educativos, vocacionales y para consumidores de drogas, se muestra muy escéptico y crítico en cuanto a su alcance e impacto:

...la rutina del encarcelamiento [...] no es brutal, peligroso ni excesivamente cruel. Es altamen-

${ }^{21}$ En este y otros sentidos, la “prisión-almacén” actual difiere de la "Gran Casona” (Big House) que era típica del sistema penal estadounidense a principios del Siglo XX (Irwin, 1980) te controlada, limitada, monótona, y carente de oportunidades para el mejoramiento del ser. (Irwin, 2004, p. 80, subrayado en el original)

En la medida en que su mirada se restrinja a Estados Unidos, la caracterización proporcionada por Irwin es quizás de mayor validez como descripción de las tendencias actuales en el diseño del ámbito penal, y no como un perfil preciso de todos los establecimientos penales y sus regímenes internos. La simple inercia histórica inherente a cualquier sistema penal, que se materializa en edificaciones que provienen de distintas épocas anteriores, es suficiente para impartir cierta variabilidad al sistema penal de un país. Por lo demás, los estudiosos canadienses quizás objetarían que los penales de ese país no constituyen "prisiones-almacenes”, dado que el gobierno canadiense ha hecho mayores esfuerzos por desarrollar, en vez de minimizar, los programas de tratamiento y rehabilitación(Meyer y O’Malley, 2005). En consecuencia, es algo problemático hablar de la “prisión-almacén” como si esta fuera el único modelo de establecimiento penal en América del Norte.

Ahora bien, si la noción de la "prisiónalmacén” ha sido tratada con cierta amplitud en América del Norte, no así la idea del penal como campo deconcentración en el mediolatinoamericano, lo cual refleja ,en parte (y una vez más), la menor producción investigativa en esta última región. Efectivamente, Caldeira (2000, p. 176) comentó que las fotografías de las víctimas de la masacre de Carandiru (ver la nota 15 supra) ofrecían "una visión de tipo campo de concentración”. Wacquant (2003, p. 200) también utilizó el término en un ensayo sobre los penales brasileños para describirlos como "campos de concentración para los desposeídos”, aunque este recurso semántico pareció emanar de su indignación moral, más que de una mirada analítica. Más interesante, porque la narrativa es menos moralista, cuando Kane fue recluido en un penal venezolano, su "primera impresión era de un campo de concentración” (Kane y Tilsley, 2006, p. 69). Sin embargo, ninguno de estos autores desarrolla o analiza la idea del campo de concentración. ¿La misma constituye una metáfora o una descripción? 
En diversas regiones del mundo, y en diversos momentos históricos, el término campo de concentración ha sido empleado para denominar una gama de instituciones que varía según el tipo de persona allí recluida, la forma en que estas personas son canalizadas hacia el establecimiento y los objetivos asignados al mismo (Applebaum, 2001). Algunos han albergado a personas de un solo estatus y tipo (como por ejemplo, los integrantes de la oposición el régimen de turno); otros han sido utilizados para una heterogeneidad de personas (como por ejemplo, los criminales, los vagos y los opositores al régimen). Y otros han sido centros de confinamiento de personas de ambos sexos y variadas edades. Algunos internos en los campos de concentración han llegado como resultado de grandes operativos de detención; otros han llegado allí después de audiencias judiciales (normalmente muy breves). Algunos campos de concentración han sido diseñados como simples depósitos de seres humanos, otros como centros de explotación de mano de obra cautiva, y otros como instrumentos de "reeducación”. ${ }^{22}$ Quizás lo único que distingue el campo de concentración de otros tipos de confinamiento es que no fue diseñado para alojar principal y únicamente a delincuentes, ni representa una respuesta específicamente enfocada, con mayor o menor grado de elaboración conceptual y teórica, al problema de la criminalidad. Y si esta es la historia semántica y materialización típica del "campo de concentración”, difícilmente se puede emplear el término para caracterizar a los establecimientos penales de América Latina, porque, evidentemente, funcionan como parte del aparato de justicia penal.

No obstante lo anterior, las alusiones esporádicas al campo de concentración en la literatura sobre los establecimientos penales de América Latina podría apuntar hacia algo importante. Puede ser que los penales no sean campos de concentración pero, posiblemente, tampoco sean prisiones o cárceles. Al comparar las características de los establecimientos

${ }^{22}$ Seis campos de concentración construidos por el régimen Nazi en Europa fueron destinados explícitamente al exterminio. Los demás campos de concentración organizados por los Nazis no fueron centros de exterminio, aunque muchas personas murieron allí (Applebaum, 2001). penales en América del Norte y América Latina, encontramos algunas diferencias claramente observables. En el Norte, los internos están sometidos a mayores niveles de vigilancia, control y aislamiento, y participan mucho menos en la organización y conducción de la vida al interior del penal. Los establecimientos penales norteamericanos están mucho más abiertos a la mirada externa y sus burocracias son mucho más formalizadas. En América Latina, el interno experimenta menores niveles de control, menor vigilancia y menor aislamiento; a la vez, juega un mayor papel en la organización y conducción de la vida al interior. Los establecimientos penales latinoamericanos están menos expuestos a la mirada externa y sus burocracias están menos formalizadas.

La manera cuantitativa de expresar estas diferencias es en términos del nivel de control: en América del Norte, el control es asiduo, en el sentido de persistente, intrusivo y casi permanente; en América Latina, el control es somero, en el sentido de esporádico, indiferente y superficial. Pero otra manera de expresar estas diferencias es cualitativa, la cual remite a la naturaleza de la privación de la libertad. Y si, en América del Norte, se habla de prisiones y encarcelamiento, en América Latina parece mejor hablar de internados judiciales e internación.

Pese a la existencia por mucho tiempo de la palabra "prisión", hay gran utilidad en el planteamiento de Foucault (1979), en el sentido de que, desde finales del Siglo XVIII, es conveniente distinguir entre el encarcelamiento y la detención, porque el primero involucra "la transformación técnica de los individuos" (1979, p. 233): "el margen por el cual la prisión excede la detención se llena [...] con técnicas de tipo disciplinario." En otras palabras, la prisión representa una institución donde no solamente se detiene a la persona, sino que también se hace algo a ella mediante "proyectos, mejorías, experimentos, planteamientos teóricos, evidencia personal e investigaciones" (Foucault, 1979, p. 235). No importa que el contenido de la transformación técnica haya cambiado con el tiempo, desde la 
rehabilitación (Rothman, 1995) hacia el castigo o la incapacitación (Feeley y Simon, 1992); no importa que estas transformaciones no se hayan materializado (como se evidencia en las denuncias periódicas sobre el "fracaso" de las prisiones). Aun cuando el encarcelamiento se restrinja al control, todavía es más que la simple detención: "Los internos no controlan nada de lo que ocurre al interior del establecimiento. Todo está estructurado conforme a políticas y reglamentos estrictos." (Bruton, 2004, p. 41). Desde estas perspectivas, el encarcelamiento se concibe como un acto de ingeniería social. Puede ser sea posible transformar al delincuente mediante la penitencia, la rehabilitación o el tratamiento; pero, cuando esto no sea posible, todavía es dable actuar de una manera racional, planificada y deliberada para reducir el desorden, el riesgo y el peligro. En este último caso, no se crea un mero almacén o depósito, se crea una "prisión-almacén".

Con gran frecuencia, los establecimientos penales latinoamericanos se denominan "prisiones" y se discuten en términos de las posibilidades (y dificultades) para rehabilitar a sus internos (Aguirre, 2005; Salvatore y Aguirre, 1996a). Sin embargo, sus características y funcionamiento debilitan la utilidad del término prisión y - retomando la sugestividad del "campo de concentración - los hace más similares a los centros de internamiento. En este sentido, las descripciones de los centros de internamiento en Estados Unidos en tiempos de guerra (ver, por ejemplo, Glidden, 1973; Hayashi, 2004) ponen de manifiesto algunas semejanzas - la infraestructura precaria, las condiciones de vida muy duras, la auto-regulación por parte de los internos, los disturbios protagonizados por estos, y el objetivo primordial de confinamiento (en vez de tratamiento o castigo) con los establecimientos penales latinoamericanos y subraya las diferencias entre estos y las actuales prisiones en América del Norte. Quizás la denominación “Internado Judicial” (empleado por lo menos en Venezuela - teóricamente - para cierto tipo de establecimiento) apunta hacia algo similar. Los establecimientos penales latinoamericanos no representan proyectos sostenidos para "la transformación técnica del individuo" (Foucault, 1979, p. 233), son centros para la detención de delincuentes, sospechosos o convictos. En el marco de la penología contemporánea, los penales de América Latina no son "prisiones-almacenes", sino simples depósitos.

Los que han estudiado la historia de los establecimientos penales en América Latina proporcionan datos útiles sobre el surgimiento y difusión de las ideas sobre las penitenciarías y las prisiones como proyectos sociales y políticos (del Olmo, 1981; Salvatore y Aguirre, 1996a; Aguirre, 2005). En sus recuentos, encontramos amplias evidencias de expertos, comentaristas y reformadores, quienes, acatando lo mejor de la ingeniería social, elaboraban visiones de la prisión como un ambiente para la transformación técnica de los delincuentes. La mayoría de estas iniciativas se nutrieron de fuentes internacionales, pero muchas también desarrollaron perspectivas con sabor local e idiosincrático. Sin embargo, las evidencias indican que las visiones e imaginarios duraban poco después de materializarse en edificios y regímenes penales (ver, especialmente, Aguirre, 2005; Salvatore y Aguirre, 1996b; Santiago-Valles, 1996). Cualquiera que fuera la causa, el margen por el cual estos regímenes superaron la mera detención para convertirse en la prisión, descrita por Foucault, era poco o ninguno. La información presentada en este ensayo también sugiere que la misma situación permanece hasta el presente.

\section{CONCLUSIÓN}

Podría objetarse que la brecha entre lo pautado y lo que realmente ocurre es común a todas las instituciones penales. Su vida, especialmente la del "sub-mundo" de los internos, no transcurre conforme a lo prescrito por reformadores, legisladores y administradores. Quizás hay pocas diferencias entre los regímenes penales de América del Norte y América Latina: cada región cuenta con un imaginario penal y cada una tiene una 
realidad penal distinta. En cierto sentido, ese planteamiento es irrefutable - porque destaca una semejanza evidente -, pero a la vez es trivial. Por lo demás, los datos presentados aquí sugieren que las realidades penales son bastante distintas en América del Norte y América Latina, y requieren mayor exploración y explicación.

Las diferencias apuntadas podrían provenir de varias fuentes. Una es la percepción de la delincuencia y la criminalidad en cada región. ¿Cuáles son las imágenes del delincuente típicamente construidas? ¿Cómo se entrelazan las creencias empíricas sobre las causas del delito y las valoraciones morales del delito? Las respuestas a estas interrogantes requerirían no solamente un estudio de las actitudes sociales, sino también de la naturaleza y el contenido de la criminología. Quizás hay diferencias apreciables entre las dos regiones en cuanto al nivel de atención enfocada hacia las causas de la criminalidad (porque muchos proyectos que se orientan hacia la transformación del delincuente se anclan en ideas sobre las causas del delito). En cambio, podría haber diferencias considerables en el tipo de causa estudiada en cada región (porque algunas causas son más susceptibles que otras a la manipulación a través de la intervención). O posiblemente hay diferencias en la imagen moral de los delincuentes y las respuestas ante el delito que se construyen a partir de ellas.

Una segunda fuente de diferencia podría ubicarse en las concepciones de la intervención organizada, sobre todo la de tipo gubernamental, en los asuntos sociales e individuales, y el grado en que la ingeniería social - del tipo insinuado por la noción focaultiana de la transformación técnica - haya echado raíces en cada región. Los centros de internamiento en América Latina parecen reflejar un desarrollo más débil de la posibilidad (y quizás la conveniencia) de una acción racional y planificada que persigue la transformación de los internos. ¿Hasta qué punto existe esa diferencia y cómo se relacionaría con concepciones distintas de la acción gubernamental e individual y con las percepciones sobre la capacidad de moldear las condiciones individuales y sociales?
Finalmente, la diferencia entre el encarcelamiento y el internamiento podría provenir de factores organizacionales, especialmente la disposición (o no) del personal penal de traducir proyectos institucionales abstractos en patrones específicos de comportamiento. La brecha universal entre el proyecto penal y la realidad penal parece estar más ancha en América Latina, por lo menos cuando se comparan las pautas legales y administrativas con lo que sucede al interior de los establecimientos penales (aunque el imaginario penal popular podría anclarse más en los hechos que en los proyectos). Quizás esta situación sea el producto de un proceso de socialización institucional más débil en América Latina, y un sentido más atenuado de la institución como un sitio de organización colectiva para el logro de objetivos universalistas.

Aun cuando se pudieran presentar y discutir brevemente casos y ejemplos relacionados con los temas de análisis planteados por estas interrogantes, en realidad constituyen líneas de investigación bastante amplias que difícilmente se pueden abordar en el marco de un ensayo. Es evidente que la comprensión adecuada de las instituciones penales requiere de un análisis sostenido de las percepciones sociales, la moralidad, la actividad intelectual y la organización institucional.

(Recebido para publicação em julho de 2009) (Aceito em dezembro de 2009)

\section{REFERENCIAS}

AGUIRRE, Carlos. The Criminals of Lima and Their Worlds. The Prison Experience, 1850-1935. Durham, NC: Duke University Press. 2005.

ALDANA, Juan Sebastián Retén de Catia. Caracas: Editorial Fuentes. 1972.

APPLEBAUM, Anne. "A History of Horror." The New York Review of Books Vol. 48, No. 16. Consultado 21/09/07. Disponible en: http://www.anneapplebaum.com/ communism/2001/10_18_nyrb_horror.html. 2001.

BAYER, Tulio. Gancho Ciego. 365 Noches y una Misa en la Cárcel Modelo. Medellín, Colombia: Ediciones Hombre Nuevo. 1978. 
BECK, Theodis. The 2005 Correctional Officer: New Roles, New Inmates, New Challenges. Presented to the Commission on Safety and Abuse in America's Prisons on November 1-2, 2005, St. Louis, Missouri. New York, NY: Vera Institute of Justice, Commission on Safety and Abuse in America's Prisons. Consultado 09/04/07. Disponible en: http://www.prisoncommission.org/ statements/beck.pdf. 2005.

BERGMAN, Marcelo. Cárceles en México. Un Estado de Situación. Informe Presentado para el Proyecto Prisons in Crisis: Understanding Latin America's Most Explosive Problem. Submitted by the Law, Jurisprudence, and Society Section of LASA. Mexico: CIDE. Consultado 10/04/07. Disponible en: http://darkwing.uoregon.edu/ caguirre/ bergman_mexico.pdf. 2004.

BJS (Bureau of Justice Statistics) Census of Jails, 1999. Washington: Bureau of Justice Statistics, NCJ 186663 Consultado 13/03/07. Disponible: http:// www.ojp.usdoj.gov/bjs/pub/pdf/cj99.pdf. 2001.

Census of State and Federal Correctional Facilities, 2000. Washington: Bureau of Justice Statistics, NCJ 198272. Consultado 26/02/07. Disponible: http:// www.ojp.usdoj.gov/bjs/pub/pdf/csfcf00.pdf. 2003.

BOP (Bureau of Prisons). Policy Documents. Washington, DC: Federal Bureau of Prisons. Consultado 9/04/07. Disponible en: http://www.bop.gov/DataSource/execute/ dsPolicyLoc. 2007.

BRETAS, Marcos L. "What the Eyes Can't See: Stories from Rio de Janeiro's Prisons.” Pp. 101-122 en The Birth of the Penitentiary in Latin America, compilado por Ricard Salvatore y Carlos Aguirre. Austin, TX: University of Texas Press. 1996.

BRICEÑO-LEÓN, Roberto; CAMARDIEL, Alberto y Olga Avila . Attitudes Toward the Right to Kill in Latin American Culture" Journal of Contemporary Criminal Justice V. 22 , n.4, P. 303-323. 2006.

BRUTON, Warden James H. The Big House. Life Inside a Supermax Security Prison. Stillwater, MN: Voyageur Press. 2004.

CAIMARI, Lila. Apenas un Delincuente. Crimen, Castigo y Cultura en la Argentina, 1880-1955. Buenos Aires: Siglo XXI. 2004.

CALDEIRA, Teresa P.R. City of Walls. Crime, Segregation and Citizenship in São Paulo. Berkeley: University of

CAMPO VÁSQUEZ, Rafael; ROA, Rosa Margarita Vargas de. World Factbook of Criminal Justice Systems: Republic of Colombia. Washington: Bureau of Justice Statistics, NCJ 199271. Consultado 26/02/07. Disponible en: http:/ /www.ojp.usdoj.gov/bjs/pub/ascii/wfcjsco.txt. 2003. Inside a Private Prison. New York, NY: New York University Press. 2006.

CARRANZA, Elías. Sobrepoblación Penitenciaria en América Latina y el Caribe: situación y respuestas posibles. p. ¿ 11-47 en Justicia Penal y Sobrepoblación Penitenciaria. - Respuestas Posibles, compilado por Elías Carranza. Mexico: Siglo XXI. 2001.

CARRANZA, Elías, et al. El Preso Sin Condena en Améri ca Latina y el Caribe. San José, Costa Rica: ILANUD. 1983. CDCR (California Department of Corrections and ↔ Rehabilitation). Inmate Visiting Guidelines. Sacramento, CA I California Department of Corrections and Rehabilitation. Consultado 14/03/07. Disponible en: http://www.cya.ca.gov/ Visitors/docs/InmateVisitingGuidelines.pdf. 2007.

COLVIN, Mark. The Penitentiary in Crisis: From Accommodation to Riot in New Mexico. Albany, NY: SUNY Press. 1992
COMFORT, Megan L. In the Tube at San Quentin. The 'Secondary Prisonization' of Women Visiting Inmates. Journal of Contemporary Ethnography. v. 32, n. 1, p. 77107. 2003.

CÓRDOVA, Tito León. Sabaneta. La Casa donde Crecen las Sombras. Maracaibo, Venezuela: Universidad del Zulia. 1999.

CSC (Correctional Service of Canada). Private Family Visiting. Ottawa, Canada: Correctional Service of Canada. Cat. No. PS84-1/2004. Consultado 14/03/07. Disponible en: http://www.csc-scc.gc.ca/text/pblct/visit/ index_e.shtml. 2007a.

CSC (Correctional Service of Canada) Home Page. Ottawa, Canada: Correctional Service of Canada. Consultado 14/03/07. Disponible en: http://www.csc-scc.gc.ca/ 2007b.

CSC (Correctional Service of Canada). Policy and Legislation. Ottawa, Canada: Correctional Service of Canada. Consultado 09/04/07. Disponible en: http:// www.csc-scc.gc.ca/text/legislat_e.shtml. 2007c.

DEL OLMO, Rosa. América Latina y su criminología. Mexico: Siglo XXI. 1981.

, Rosa. The State of Prisons and Prisoners in Four Countries of the Andean Region. p. 115-139 en Comparing Prison Systems. Toward a Comparative International Penology, compilado por Robert P. Weiss y Nigel South. Amsterdam, NL: Gordon and Breach. 1998.

DÍAZ-COTTO, Juanita. Gender, Ethnicity and the State: Latina and Latino Prison Politics. Albany, NY: SUNY Press. 1996.

FEELEY, Malcolm M.; SIMON, Jonathan. The New Penology: notes on the emerging strategy of corrections and it implications. Criminology. v. 30, n. 4, p. 449-474. 1992.

, Malcolm L.; RUBIN, Edward L. Judicial policy making and the modern state: how the courts reformed America's Prisons. New York, NY: Cambridge University Press. 1999.

FLEISHER, Mark S. Warehousing Violence. Newbury Park, CA: Sage Publications. 1989.

FOUCAULT, Michel. Discipline and Punish. The Birth of the Prison. London: Peregrine. 1979.

GAES, Gerald et al. The influence of prison gang affiliation on violence and other prison misconduct. The Prison Journal, v. 82, n. 3, p. 359-385. 2002.

GARLAND, David. The culture of control. Chicago: University of Chicago Press. 2001.

GAUCHER, Bob; LOWMAN, John. Canadian Prisons” p. 61-97 en Comparing Prison Systems. Toward a Comparative International Penology, compilado por Robert P. Weiss y Nigel South. Amsterdam, NL: Gordon and Breach. 1998.

GLIDDEN, William B. Internment Camps in America, 1917-1920. Military Affairs 37(4):137-141. 1973.

GODOY, Angelina S. Popular injustice. Violence, community and law in Latin America. Stanford, CA Stanford University Press. 2006.

GOFFMAN, Erving Asylums. Essays on the social situation of mental patients and other inmates. London: Pelican. [1961] 1991.

HAYASHI, Brian M. Democratizing the Enemy: the Japanese American Internment. Princeton: Princeton University Press. 2004.

HIDALGO, Reynaldo; JORDAN, Michael (1993-1994) Amotinamientos carcelarios: de los cambios administrativos a la ruptura del control (Sabaneta, Enero de 1994). Revista Cenipec (Merida, Venezuela) n. 15, p.125-142. 
HOUSTON, Jean Wakatsuki. Farewell to Manzanar. New York: Random House. 1973.

HRW (Human Rights Watch). Prison Massacre in Maracaibo. Washington, DC: Human Rights Watch (Publication No. B601). 1994.

HRW (Human Rights Watch). Punishment before trial: prison conditions in Venezuela. New York: Human Rights Watch. 1997.

HRW (Human Rights Watch). Behind bars in Brazil. New York: Human Rights Watch. 1998.

HUGGINS, Martha K.; MESQUITA, Myriam P. MESQUITA. Scapegoating outsiders: the murders of street youth in modern Brazil. Policing and Society. v. 5, n. 4, p. 265280. 1995

INPEC (Instituto Nacional Penitenciario y Carcelario) Normas. Bogotá: Instituto Nacional Penitenciario y Carcelario. Consultado 09/04/07. Disponible en: http:// www.inpec.gov.co/normas.php. 2007.

IRWIN, John. Prisons in Turmoil. Boston, MA: Little, Brown and Company. 1980.

John. The Warehouse Prison. Disposal of the New Dangerous Class. Los Angeles, CA: Roxbury Publishing. 2004.

JACOBS, James B. Stateville: the penitentiary in mass society. Chicago: University of Chicago Press. 1977.

JORDAN, Michael. Objetivos institucionales, definición de roles y procesos de comunicación: una comparación entre las cárceles de Mérida, Venezuela y Albququerque, New Mexico, USA. p. 259-291 en Control social y justicia penal en Venezuela, compilado por Luis Gerardo Gabaldón y Christopher Birkbeck. Mérida, Venezuela: Universidad de Los Andes. 1996.

Juristat (Canadian Centre for Justice Statistics). Adult correctional services in Canada, 2004/2005. Statistics Canada - Catalogue No. 85-002-XIE, Vol. 26 No. 5. Consultado 13/03/07. Disponible en: http://www.statcan.ca/ cgi-bin/downpub/listpub.cgi? catno $=85-002-X I E 2006005$. 2006.

KANE, Frank; TILSLEY, John. In the shadow of Papillon. Seven years of hell in Venezuela's prison system. Edinburgh, UK: Mainstream Publishing. 2006.

LAPPIN, Harley. Statement of harley G. Lappin, director, Federal Bureau of Prisons, before the Commission on Safety and Abuse in America's Prisons. Presented on February 9 2006, Los Angeles, California. New York, NY: Vera Institute of Justice, Commission on Safety and Abuse in America's Prisons. Consultado 09/04/07. Disponible en: http://www.prisoncommission.org/statements/ lappin_harley_g.pdf. 2006.

LYNCH, Mona. From the punitive city to the gated community: security and segregation across the social and penal Landscape. Miami law Review. v. 56, n. 1, p. 601-623. 2001.

MACNEIL, Donald. Journey to hell. Inside the world's most violent prison system. Preston, UK: Milo Books. 2006.

MARQUART, James. The american correctional environment and prison officers. Presented to the Commission on Safety and Abuse in America's Prisons, November 1-2 2005, Saint Louis, Missouri. New York, NY: Vera Institute of Justice, Commission on Safety and Abuse in America's Prisons. Consultado 09/04/07. Disponible en: http://www.prisoncommission.org/ statements/marquart.pdf. 2005.

James; CROUCH, Ben. Coopting the Kept: using inmates for social control in a southern prison. Justice Quarterly, v. 4, n. 1, p. 491-509. 1984.
James; CROUCH, Ben. Judicial reform and prisoner control: the impact of Ruiz v. Estelle on a Texas Penitentiary. Law and Society Review, v. 19, n. 4, p. 557586). 1985.

MARTÍNEZ, J.F. Un caso de amparo penitenciario. Revista Cenipec (Mérida, Venezuela) n. 15, p. 65-96. 1993-1994.

McCARTNEY, James L. Classification of Prisoners. Psychiatric quarterly. v. 7, n. 3, p. 369-377. 1933.

MELOSSI, Dario; LETTIERE, Mark. Punishment in the American Democracy: the paradoxes of good intentions. p. 21-59 en Comparing Prison Systems. Toward a Comparative International Penology, compilado por Robert P. Weiss y Nigel South. Amsterdam, NL: Gordon and Breach. 1998.

MEYER, Jeffrey; O'MALLEY, Pat Missing the punitive turn? Canadian Criminal Justice, 'Balance', and Penal Modernism." Pp. 201-217 en The new punitiveness: trends, theories, perspectives, compilado por John Pratt y otros. Cullumpton, UK: Willan Publishing. 2005.

MILLER, David. The Lord of Bellavista. London: Triangle. 1998.

MOORE, Dawn; HANNAH-MOFFATT, Kelly. The liberal veil: revisiting canadian penality. p. 85-100 en The New Punitiveness: trends, theories, perspectives, compilado por John Pratt y otros. Cullumpton, UK: Willan Publishing. 2005.

NARVÁEZ, Grimaneza. Tratamiento Penitenciario. Archivos de criminología, neuro-psiquiatría y disciplinas conexas (Quito) XXV:27. 1984.

NCDC (North Carolina Department of Correction) Assigning Inmates to Prison. Consultado 04/04/07. Disponible en: http://www.doc.state.nc.us/dop/ custody.htm. 2007.

OLIVERO, J. Michael. The Crisis in Mexican Prisons: the impact of the United States. p. 99-113 en Comparing prison systems. Toward a comparative international penology, compilado por Robert P. Weiss y Nigel South. Amsterdam, NL: Gordon and Breach. 1998.

PEREA, Carlos M. El Territorio es Sagrado. Pandillas y Guerras del Pavimento en Colombia. p. 355-375 en Elementos para una Criminología Local. Políticas de Prevención del Crimen y la Violencia en Ambitos Urbanos, compilado por María Victoria Llorente y Mauricio Rubio. Bogotá: Alcaldía Mayor, Secretaría de Gobierno. 2003.

REISIG, Michael D. Rates of disorder in higher-custody state prisons: a comparative analysis of managerial practices. Crime and deliquency. v. 44, n. 2, p. 229-244. 1998.

RICO, José María. Crimen y justicia en América Latina. Mexico: Siglo XXI. 1977.

, José María. Costa Rica. En World factbook of criminal justice systems. Washington: Bureau of Justice Statistics, NCJ 199273. Consultado 26/02/07. Disponible en: http://www.ojp.usdoj.gov/bjs/pub/ascii/wfcjscr.txt. 2003.

RIDEAU, Wilbert; WIKBERG, Ron. Life sentences. Rage and Survival Behind Bars. New York, NY: Times Books. 1992.

RIVELAND, Chase. Prison Management Trends, 19752025. Crime and Justice, n. 26, p. 163-203. 1999.

ROBERTSON, James. Houses of the dead: warehouse prisons, paradigm change and the Supreme Court. Houston Law Review, n. 34, p. 1003-63. 1997.

ROTHMAN, David J. Perfecting the prison: United States, 1789-1965. p. 117-150 en The Oxford History of the Prison, 
compilado por Norval Morris y David J. Rothman. Oxford: Oxford University Press. 1995.

ROTKER, Susana (Ed.) Ciudadanías del Miedo. Caracas: Editorial Nueva Sociedad. 2000.

SHILS, Edward. The Theory of Mass Society. Diogenes 10(39):45-66. 1962 .

SALVATORE, Ricardo; AGUIRRE, Carlos (Eds.). The birth of the penitentiary in Latin America. Austin, TX University of Texas Press. 1996a.

The birth of the penitentiary in Latin America: toward an interpretive social history of prisons. p. 1-43 en The birth of the penitentiary in Latin America, compilado por Ricardo Salvatore y Carlos Aguirre. Austin, TX University of Texas Press. 1996b.

SANTIAGO-VALLES, Kelvin A. Forcing them to work and punishing whoever resisted: servile labor and penal servitude under colonialism in nineteenth century Puerto Rico. p. 123-168 en The birth of the penitentiary in Latin America, compilado por Ricardo Salvatore and Carlos Aguirre. Austin, TX: University of Texas Press. 1996.

SIMON, Jonathan. From the big house to the warehouse: rethinking prisons and state government in the $20^{t}$ Century. Punishment and society. v. 2, n. 2, p. 213-234, 2000.

SPFA (Sistema Penitenciario Federal Argentino) Legislación. Buenos Aires, Argentina: Ministerio de Justicia y Derechos Humanos. Consultado 09/04/07. Disponible en: http://www.spf.gov.ar/FramePPal/ Legislacion/Newlegislacion.htm. 2007.

SWEDBERG, Claire. LA County Jail to Track Inmates. RFID Journal, May 16, 2005 Consultado 04/04/07. Disponible en: http://www.rfidjournal.com/article/ articleview/1601/1/1/. 2005.
TEETERS, Negley G. Penology from Panama to Cape Horn. Philadelphia, PA: University of Pennsylvania Press/Temple University Press. 1946.

TOCH, Hans. Warehouses for people? Annals of the American Academy of Political and Social Science. n. 478 , P. 58-72. 1985

TOCORA, Fernando. La reforma procesal penal en América Latina. Capítulo Criminológico (Maracaibo, Venezuela) v. 33, n. 4, p. 445-468. 2005.

UNITED NATIONS. The eighth United Nations survey on crime trends and the operations of criminal justice systems (2001-2002). New York: United Nations. Consultado 04/ 04/07. Disponible en: http://www.unodc.org/unodc/ crime_cicp_survey_eighth.html. 2005.

VENEZUELA. Código Penal. Caracas: Gaceta Oficial, n. 915, Extraordinario. 1964

Reglamento de internados judiciales. Caracas: Gaceta Oficial, n. 30.784. 1975

Ley de régimen penitenciario. Caracas: Gaceta Oficial, n. 36.975. 2000 .

Código Penal. Caracas: Gaceta Oficial, n. 5.768, Extraordinario. 2005.

VOGLER, Richard. A World View of Criminal Justice. Aldershot, UK: Ashgate Publishing. 2005.

WACQUANT, Loïc. Toward a dictatorship of the poor? Notes on the Penalization of Poverty in Brazil. Punishment and Society v. 5, n. 2, p. 197-205. 2003.

WERNER, Trish. Modern Lockdown. Security products November 2006:22. Consultado 07/03/07. Disponible en: http://www.secprodonline.com/articles/41647/. 2006. 
PRISONS AND INTERNMENT: a comparison of penal facilities in North America and Latin America

\section{Christopher Birkbeck}

The recent use of expressions such as "warehouse prison" in the U.S. and "concentration camp" in Latin America would seem to indicate that conditions of deprivation of freedom in both regions look more and more alike. The analysis presented here suggests that it is not so. Penal institutions in North and South America throughout six interrelated dimensions are compared: internal organization of the places, surveillance, isolation, supervision, administrative control and formalization of procedures. In North America, control is deep (persistent, intrusive and almost permanent); in Latin America, control is shallow (sporadic, indifferent and superficial). If in North America one speaks of prisons and incarceration, in Latin America it seems better to speak of judicial inmates and internment.

KeYwORDS: prison, internment, North America, Latin America.
PRISONS ET INTERNES: une comparaison des etablissements pénitentiaires en Amérique du Nord et en Amérique Latine

\section{ChristopherBirkbeck}

L'utilisation récente de termes tels que "prison d'entrepôt" aux Etats-Unis et "camp de concentration" en Amérique Latine semblerait indiquer que les conditions de détention dans ces deux régions du monde sont de plus en plus similaires. Cependant l'analyse réalisée à ce sujet suggère le contraire. La comparaison entre les prisons en Amérique du Nord et en Amérique Latine a été faite à partir de six critères interdépendants: l'organisation interne de l'espace, la surveillance, l'isolement, le contrôle de gestion et les procédures. En Amérique du Nord, le contrôle est assidu (persistant, intrus et pratiquement permanent), en Amérique Latine, le contrôle est apparent (sporadique, indifférent et superficiel). Si en Amérique du Nord, on parle de prisons et d'incarcération, en Amérique Latine, il vaudrait mieux parler d'internements judiciaires et d'internement.

Mots-CLÉs: incarcération, prison, internement, Amérique du Nord, Amérique Latine.

Christopher Howard Birkbeck - Pós-graduado pela Universidade de Oxford, Reino Unido, com doutorado na Universidade de Gales. Foi professor e pesquisador em criminologia na Universidad de los Andes entre 1980 e 2006. Em várias ocasiões, foi professor ou pesquisador convidado da Universidade do Novo México, nos Estados Unidos. Atualmente exerce a docência em criminologia na Universidade de Salford. Sua pesquisa atual aborda a moralização da insegurança pessoal na imprensa da América Latina e da América do Norte. 
